\title{
The professional and educational ecosystem as a driver of development collaboration between engineering education and production
}

\author{
Mikhail Flek ${ }^{1}$, Ekaterina Ugnich $^{2}$ \\ ${ }^{1}$ Professor, D-r of Technical Sciences, Deputy Managing Director, Rostvertol PLC, «Aircraft \\ Engineering» Department Chair, Rostov-on-Don, Russia; \\ ${ }^{2}$ Docent, Ph.D., associate professor Don State Technical University, Rostov-on-Don, Russia
}

\begin{abstract}
The formation and development of human capital as to the current and future needs of production is a serious challenge for modern enterprises. Human capital, which is based on knowledge and skills, is the most important factor of production that determines the competitiveness and efficiency of the enterprise. One of the ways to solve this problem is the formation of the enterprise vocational education ecosystem, by combining with various educational organizations. The authors formulate the concept of a professional and educational ecosystem as a type of socio-economic ecosystem. The importance of interaction between ecosystem subjects as the basis for the emergence of synergistic effects is emphasized. The theoretical conclusions are supported by empirical material on the example of the professional and educational ecosystem of a large helicopter enterprise. The characteristic of the enterprise's professional and educational ecosystem is given. Emphasis is placed on the structural and specific description of the professional and educational ecosystem. The reasons for the formation of the professional and educational ecosystem of the enterprise and the way of its development are analyzed. The analysis of the effectiveness of the professional and educational ecosystem can be based on the stakeholder theory, based on the assessment of the results of the ecosystem by its main participants. In order to analyze the effectiveness of the professional and educational ecosystem of the enterprise, a survey of its participants was conducted on the importance of knowledge and skills acquired as a result of training, and satisfaction with them. On the basis of the poll results, a perceptual map was built by the analysis of Needs\&Gaps. She demonstrated the most important attributes, describing the results of the professional and educational ecosystem from the perceptual of importance and satisfaction of participants in this ecosystem. The construction of the perceptual map made it possible to draw a conclusion about the high assessment of the participants of the ecosystem of practical skills acquired in the learning process. The results of the analysis of the professional and educational ecosystem of the enterprise confirm its effectiveness in solving the problem of human capital formation.

Keywords: human capital, enterprise, professional and educational ecosystem, production system, production, engineering education, collaboration.
\end{abstract}




\section{Introduction}

In the context of the establishment of a post-industrial society and the increase in the intellectualization of the economy, a significant problem for many domestic enterprises is the gap between the required "quality" of human resources and the proposed education system. According to a study by the Boston Consulting Group, Russia ranks 89th in terms of the availability of qualified personnel. At the same time, $35 \%$ of graduates of domestic colleges and $25 \%$ of graduates of universities [6] cannot find a job in the specialty acquired, mainly due to the lack of vacancies. Moreover, for enterprises, especially high-tech, the problem of obsolescence of knowledge is relevant, since their "half-life" in science-based industries is less than 2.5 years. The solution to these and other problems is impossible without improving the mechanisms of the education system as a source of formation and development of the human capital of the enterprise - the most important production resource in which the knowledge, skills, and experience of workers are concentrated [8].

Large enterprises in different ways try to solve the problem of personnel gaps in the necessary qualifications. One such way is the creation of corporate universities. In Russia today there are more than 30 of them. Corporate universities, as a rule, implement programs of further vocational education, that is, they form only professional competencies. The "foundation" of the human capital is laid from the school bench - it is formed by the education system and family. This problem is partially eliminated by another way to improve the "quality" of the formation of the human capital - the combination of enterprise efforts with various educational organizations. Within the framework of such an association, basic departments are often created, the principle of which is based on dual practice-oriented training, which has proved its effectiveness both in Russia and abroad [19]. There is also a more complex version of such an association - the formation of the professional and educational ecosystems, which are based on the ongoing acquisition of the necessary knowledge, skills, and experience on the principle of lifelong learning.

The aim of this work is to study the features of the formation and development of the professional and educational ecosystem of the enterprise as a driver for the development of the collaboration of engineering education and production. This goal is achieved by solving the following tasks:

- reveal the essence of the professional and educational ecosystem of the enterprise and its role in the formation of the human capital of the enterprise,

- analyze the sources of formation and development of the professional and educational ecosystem on the example of a helicopter-building enterprise,

- describe the structure of the professional and educational ecosystem enterprise,

- evaluate the results of the functioning of the professional and educational ecosystem enterprise.

\section{Methods}

The inability of the existing provisions of the neoclassical economy to adequately study the dynamics of economic development, to explain the change in technological structures and scientific and production cycles [18] makes us reconsider many approaches and directions of economic theory [7]. Modern conditions for the development of the economy require new methodological approaches that can assess the feasibility of the collaboration between entities, as well as the potential of the communities of various economic agents formed on their basis. It is the systematic approach that underlies this work that allows one to create a single research space for the whole complex of socio-economic phenomena. The systemic paradigm is based on the concept of ecosystems, which originally arose in biology 
and has interdisciplinary potential. The concept of ecosystems allows one to consider it from the point of view of collaborations and interrelations between constituent components [14]. The concept of ecosystems is increasingly used to study open systems with a different number of heterogeneous participants having diverse relationships [17]. In this regard, we consider it appropriate to apply it to the study of the collaboration of the enterprise with educational organizations. The professional and educational ecosystem is a special socio-economic ecosystem. Its basis is the collaboration of participants, a network of collaborating and competing organizations that offer related products and services [1]. If in the biological ecosystem biomass is the product (result), then in the professional and educational ecosystem it is human capital.

To assess the effectiveness of the professional and educational ecosystem in this study, we used the theory of stakeholders [13] and a direct subjective methodology [5], based on the assessment of the ecosystem's results by its main participants, as well as a situational analysis method [20], which allows studying current phenomena in real conditions. The empirical basis for evaluating the effectiveness of the professional and educational ecosystem of Rostvertol PJSC is the results of a survey conducted at the end of 2018 of four different groups of its various participants regarding the importance and satisfaction of the knowledge and skills that are forming in this ecosystem, which form the basis of the human capital of the enterprise. Based on the results of the questionnaire, a perception map was constructed using the Needs \& Gaps analysis method [15], which was able to clearly demonstrate the advantages and disadvantages of the functioning of the professional and educational ecosystem, as well as its development reserves.

\section{Results}

In determining the content of socio-economic ecosystems, which include professional and educational, it is necessary to emphasize the simultaneous implementation of cooperation and competition. Since there is no common understanding of the socio-economic ecosystem, specifying the most capacious definition of G.B. Kleiner [2], we define professional and educational ecosystem as a complex dynamic system, geographically localized, consisting of the collaboration entities that create a specific product (result) and implement processes of cooperation and competition simultaneously with the formation of synergistic effects. Based on this definition, a professional and educational ecosystem is not just a combination of educational institutions with a partner enterprise but their complex dynamic formations, where synergistic effects are achieved - effects when the effectiveness of the system increases due to the collaboration of its various elements in nature. The prefix "eco" to the word "system" in this case emphasizes the need for a certain collaboration environment for participants based on their horizontal connections, where synergistic effects arise.

The socio-economic ecosystem, according to G.B. Kleiner [3], includes four components: organizational, infrastructure, communication and logistics, and innovation (Fig. 1). Thus, the organizational component is a combination of organizations and independent individuals functioning as part of an ecosystem. This component can be described as a cluster. The infrastructural component is the mechanisms, rules, and regulations that shape the environment of its participants. The communication and logistics component is characterized by integration and communication mechanisms that ensure the process of the collaboration between participants. The innovative component represents innovative impulses, that is, measures aimed at adapting the ecosystem to changes in the external environment. From this perspective, one can characterize the professional and educational ecosystem (Fig. 1). 


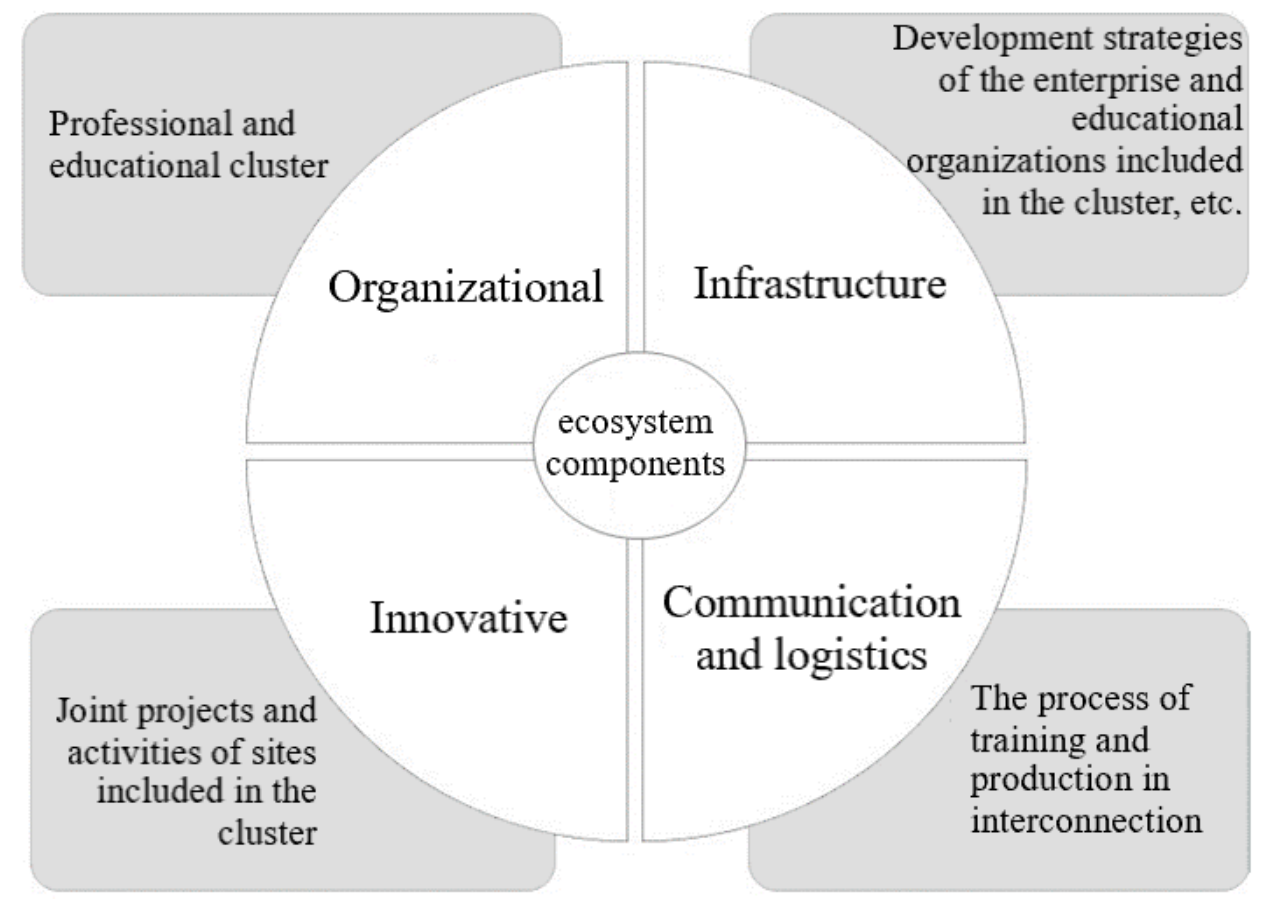

Fig. 1. The components of the professional and educational ecosystem.

Thus, the successful functioning of the professional and educational ecosystem is ensured by the collaboration of various components and their reproduction. The main direction of all components of the professional and educational ecosystem is the joint creation of value human capital of the enterprise [11].

An illustration of an example of the professional and educational ecosystem of PJSC Rostvertol, the largest helicopter-building enterprise included in the Russian Helicopters holding, allows one to demonstrate the specifics of this mechanism in the formation of the human capital of the enterprise. The search for ways to solve the problem of matching the "quality" of the human capital of the enterprise to its current and future production tasks led to the fact that in 2002, enterprise initiated the creation of an educational space, which was then transformed, in 2015, into a professional and educational cluster, which at the moment is already a professional and educational ecosystem.

The main reasons for creating enterprise educational space in 2002 are:

- the need for continuous training of workers in view of the special nature of the enterprise - the manufacturer of aviation equipment — due to the continuous updating of the range and modification of manufactured products, the development of new technologies, materials, and high-tech equipment;

- the need for confidentiality in the transfer of knowledge and the formation of qualified personnel, dictated by the specifics of the military-industrial complex;

- natural aging and the departure of qualified engineers from production amid worsening labor mobility throughout the country.

Specialized colleges, schools, and, founded in the same year 2002, together with Don State Technical University (DSTU) the basic department of Aircraft Engineering, became participants of the educational space of PJSC Rostvertol. 
In the future, as a result of strengthening the relationships between the participants of the educational space, it was transformed into a professional and educational cluster (Fig. 2). The fundamental difference between the educational space and the professional and educational cluster is that in the first there is no concentration of efforts in a certain area, there are no strong relationships between the participants, the organizational structure is not structured.

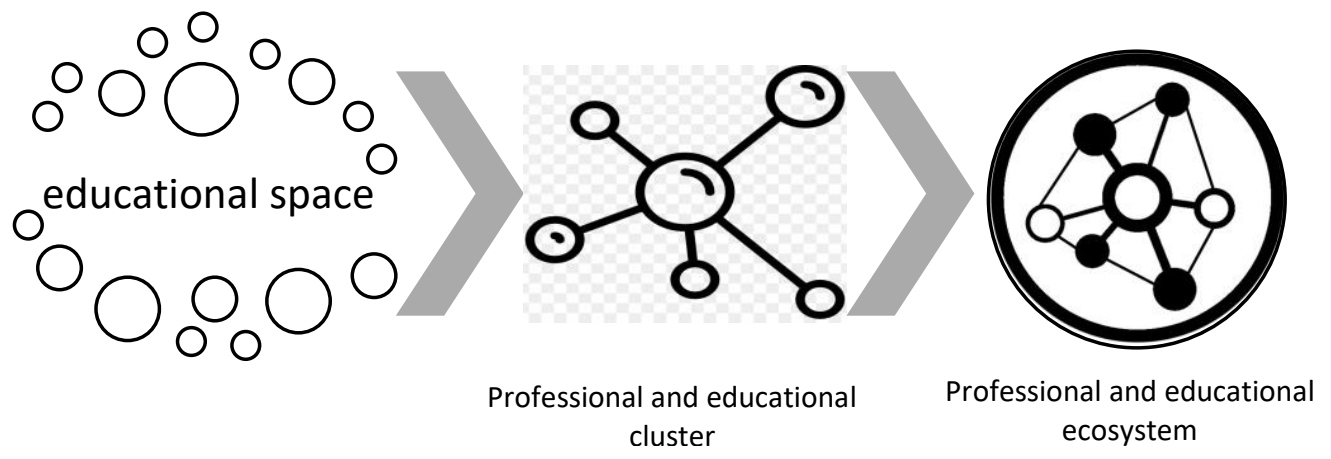

Fig. 2. Formation of a professional and educational ecosystem (space - cluster - ecosystem)

The goal of the professional and educational cluster of PJSC Rostvertol is to develop an integrated training system for workers and specialists for the aviation industry along the chain "Secondary general education - Secondary vocational education - Higher education - Further professional education". Thus, the formation of a future specialist occurs starting from school. Participants of the professional and educational cluster [9] are presented in table 1.

Table 1. Professional and educational cluster members

\begin{tabular}{|c|c|c|}
\hline Organization level & $\begin{array}{c}\text { Representative } \\
\text { organizations }\end{array}$ & Main functionality \\
\hline \multicolumn{3}{|c|}{ Basic educational organizations } \\
\hline $\begin{array}{l}\text { Secondary general } \\
\text { education }\end{array}$ & $\begin{array}{l}\text { sponsored schools of Rostov- } \\
\text { on-Don }\end{array}$ & $\begin{array}{l}\text { Lay the "foundation" of the human } \\
\text { capital, provide entrants with } \\
\text { subsequent cluster links }\end{array}$ \\
\hline $\begin{array}{l}\text { Secondary } \\
\text { vocational } \\
\text { education }\end{array}$ & $\begin{array}{l}\text { Don Industrial and Technical } \\
\text { College. BN Slusar; Aviation } \\
\text { college }\end{array}$ & $\begin{array}{l}\text { Training aviation industry workers } \\
\text { and specialists for enterprise }\end{array}$ \\
\hline Higher education & $\begin{array}{l}\text { DSTU: basic department of } \\
\text { Aircraft Engineering }\end{array}$ & $\begin{array}{l}\text { Training of qualified specialists with } \\
\text { higher education in the aviation } \\
\text { industry for enterprise }\end{array}$ \\
\hline $\begin{array}{l}\text { Further professional } \\
\text { education }\end{array}$ & $\begin{array}{l}\text { DSTU: Institute of Aviation } \\
\text { Industry Management and } \\
\text { Innovation }\end{array}$ & $\begin{array}{l}\text { Additional professional training and } \\
\text { retraining of enterprise workers, } \\
\text { advanced training, the formation of } \\
\text { new competencies of workers in } \\
\text { target areas }\end{array}$ \\
\hline \multicolumn{3}{|c|}{ Structural units of the base enterprise } \\
\hline $\begin{array}{l}\text { Further professional } \\
\text { education }\end{array}$ & $\begin{array}{l}\text { Personnel Training Center, } \\
\text { Aviation Training Center }\end{array}$ & $\begin{array}{l}\text { Additional professional training for } \\
\text { enterprise } \\
\text { training }\end{array}$ \\
\hline $\begin{array}{l}\text { Non-formal } \\
\text { education in the } \\
\text { course of work }\end{array}$ & $\begin{array}{l}\text { Workshops and departments } \\
\text { of the enterprise }\end{array}$ & $\begin{array}{l}\text { Practice and exchange of experience } \\
\text { in the workplace }\end{array}$ \\
\hline
\end{tabular}


Thus, the participants of the professional and educational cluster (Table 1) are represented not only by educational institutions from schools to universities but also by structural units of enterprise [10].

The further development of the organizational structure of the professional and educational cluster in the ecosystem is due to the turbulence of the external environment under the influence of the strengthening of integration processes and the challenges of digital production. The need for ecosystems is due to the fact that in modern conditions, to create a product that meets all the necessary requirements, it is necessary to combine the resources and competencies of several organizations. The ecosystem provides a new higher organization level for production [4]. So, if the product of the educational space is educational services, the product of the professional and educational ecosystem is human capital.

If the educational space of PJSC Rostvertol included several educational organizations that are not interconnected, then the professional and educational cluster represents an already defined organizational structure of participants based on their collaboration. The professional and educational ecosystem in addition to the totality of the participants and their collaboration, includes the environment, certain integration mechanisms that develop the collaboration of participants and the adaptation mechanism, which serves as the basis for the sustainability and self-development of the ecosystem.

The success of the professional and educational ecosystem is characterized by the effectiveness of the formation of the human capital of the enterprise. A number of researchers suggest evaluating the functioning of socio-economic ecosystems based on the development of the theory of "stakeholders" [13]. For this, it is necessary to identify parties (participants) who are interested in the effective functioning of the ecosystem, to determine their value relationships and results of activities. Mixing up the subjectivity of stakeholders, a definite assessment system is formed that characterizes the effectiveness of the functioning of the socio-economic ecosystem. The effectiveness of a professional and educational ecosystem should be evaluated, first of all, on the basis of availability and satisfaction with knowledge and skills that make up the human capital of the enterprise [12]. Among the "stakeholders" of the professional and educational ecosystem, four main groups can be distinguished:

- executives of the enterprise and its structural divisions;

- professors of educational organizations of the enterprise;

- enterprise workers (graduates, previously trained in educational organizations of the professional and educational ecosystem);

- students currently studying in the educational organizations of this ecosystem.

In order to analyze the effectiveness of the system of education and training of specialists in the professional and educational ecosystem of PJSC Rostvertol, in November 2018, a survey of representatives of these four groups of participants was conducted. On a five-point scale, respondents rated the importance and satisfaction of the results of training in a professional and educational ecosystem:

- general professional knowledge necessary for an engineer,

- special professional knowledge directly related to the aircraft industry,

- general cultural knowledge,

- practical skills.

The survey results of four groups of respondents are presented in table 2 .

In general, all groups gave a satisfactory rating (at least 3 points) of both importance and satisfaction with knowledge and skills. The high importance of specialized professional knowledge was noted by enterprise executives (4.92) with a satisfaction value of 4.31 . The least satisfaction with knowledge, both general professional and special, was noted by graduates - enterprise workers (values 3.39 and 3.56, respectively). They are also the least satisfied with the practical skills acquired in the learning process (3.74). This can be explained by the rapid obsolescence of specialized knowledge. 
Table 2. Survey results on the importance and satisfaction of knowledge and skills gained as a result of training

\begin{tabular}{|c|c|c|c|c|c|c|c|c|}
\hline \multirow{2}{*}{$\begin{array}{l}\text { Indicators } \\
\text { ("attributes") }\end{array}$} & \multicolumn{4}{|c|}{ importance } & \multicolumn{4}{|c|}{ satisfaction } \\
\hline & 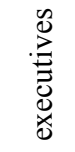 & $\begin{array}{l}0 \\
\vdots \\
0 \\
0 \\
0 \\
0 \\
\vdots\end{array}$ & 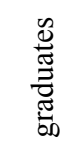 & 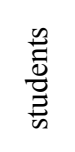 & 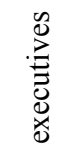 & $\begin{array}{l}\infty \\
\tilde{0} \\
0 \\
\omega \\
\omega \\
0 \\
0 \\
0\end{array}$ & 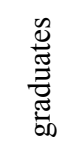 & 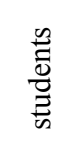 \\
\hline $\begin{array}{c}\text { General } \\
\text { professional } \\
\text { knowledge (1) }\end{array}$ & 4,65 & 4,26 & 4,02 & 4,01 & 4,58 & 3,99 & 3,39 & 3,63 \\
\hline $\begin{array}{c}\text { Special } \\
\text { professional } \\
\text { knowledge (2) }\end{array}$ & 4,92 & 4,48 & 4,27 & 4,49 & 4,31 & 4,24 & 3,56 & 4,42 \\
\hline $\begin{array}{l}\text { General cultural } \\
\text { knowledge (3) }\end{array}$ & 4,59 & 4,40 & 3,71 & 3,67 & 4,19 & 4,00 & 4,04 & 4,01 \\
\hline Practical skills (4) & 4,72 & 4,55 & 4,34 & 4,53 & 4,63 & 4,11 & 3,74 & 4,03 \\
\hline
\end{tabular}

Note. The table shows the average values according to the respondents' assessment of the importance and satisfaction with knowledge and skills on a five-point scale (5 - very important/absolutely satisfied; 1 - does not matter/absolutely not satisfied). At the same time, executives noted the importance and satisfaction of this knowledge for enterprise workers; professors - for students (future workers); department graduates (enterprise workers) and students - own knowledge.

For a more detailed description of the "quality" assessment of the human capital of the professional and educational ecosystem, we will construct a perception map by the Needs \& Gaps analysis method [15]. The Needs \& Gaps method is based on the results of respondents' assessment of importance and satisfaction with certain "attributes" on a 5-point scale. To construct a perception map, the survey results presented in Table 2 were used.

To construct a perception map, a coordinate plane was constructed for each of the four groups of respondents. Origin points (average values for importance and satisfaction for the entire set of "attributes") are presented in table 3.

Table 3. Origin points for the perception map of each group of "participants" of the professional and educational ecosystem

\begin{tabular}{|c|c|c|c|c|}
\hline Indicator & Executives & Professors & Graduates & Students \\
\hline Importance & 4,71 & 4,23 & 4,09 & 4,18 \\
\hline Satisfaction & 4,43 & 4,09 & 3,68 & 4,02 \\
\hline
\end{tabular}

Perception maps of four groups of respondents are presented in Figure 3. The numbering of "attributes" (1-4) is presented in Table 2. 


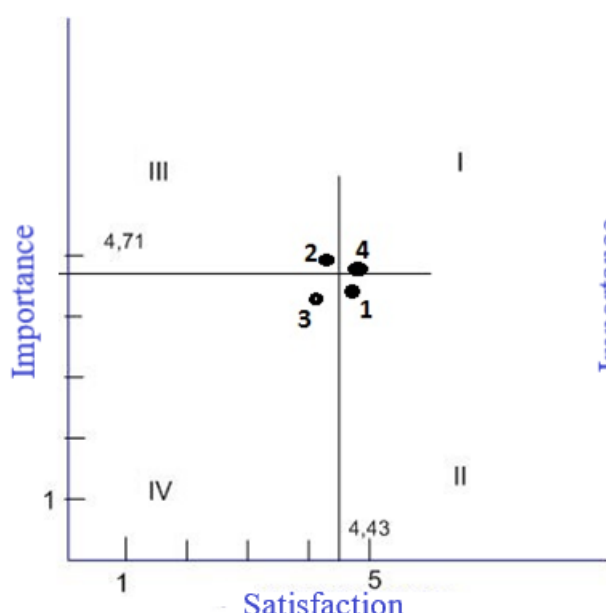

a) executives of the enterprise and its structural divisions

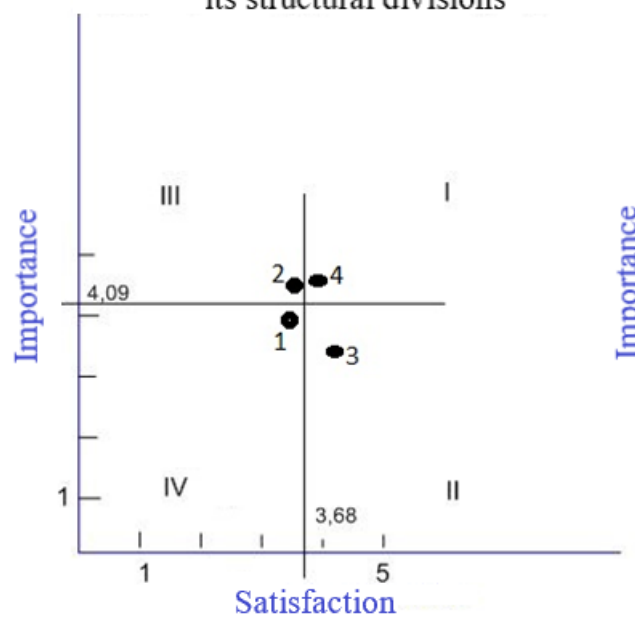

c) graduates - enterprise workers

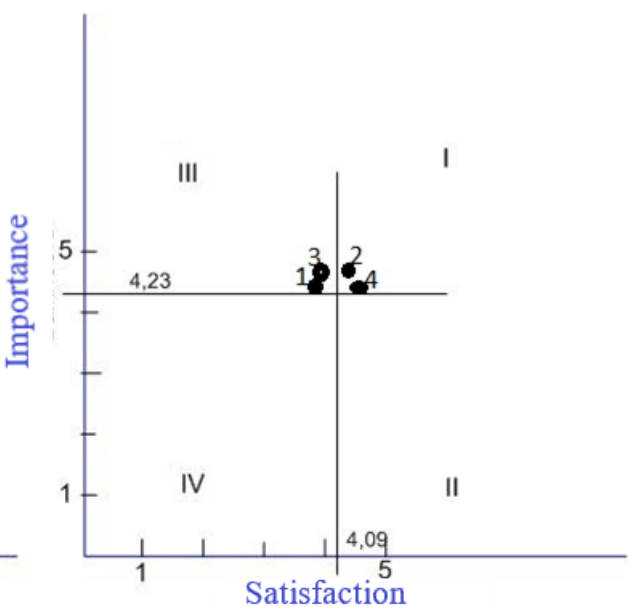

b) professors of the professional and educational ecosystem

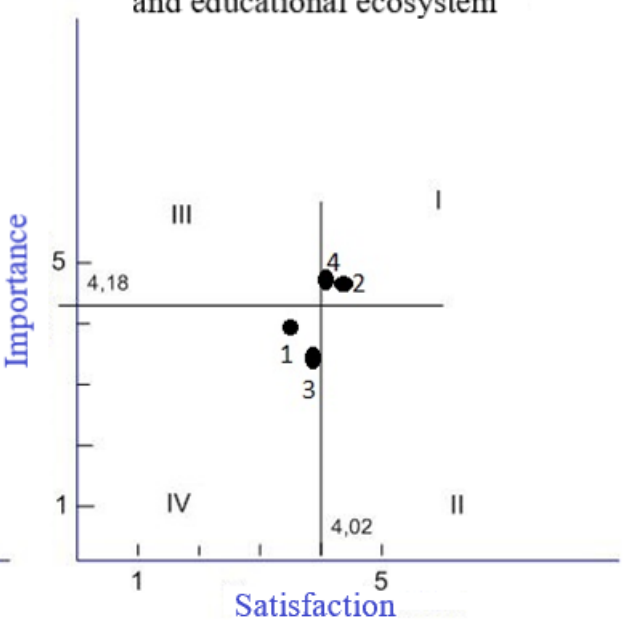

d) senior students

Fig. 3. Perception maps of participants of the professional and educational ecosystem

The upper right quadrant (I) is characterized by high importance and high satisfaction of the "attribute". The lower right quadrant (II) is the quadrant of secondary benefits or gaps. Attributes located in the second quadrant need support and development. The upper left quadrant (III) characterizes the underlying flaw. The lower left quadrant (IV) is characterized by low importance with low satisfaction. Improving the attributes located there requires more substantial efforts but is necessary for the qualitative formation of the human capital of the enterprise. It is noteworthy that all groups of respondents noted that practical skills ("attribute" 4) are the basic advantage of the professional and educational ecosystem (for all respondents, it is in quadrant I).

Analyzing the perception map, it can be noted that according to all participants in the ecosystem, its basic advantage is the acquisition of practical skills by the carriers of the human capital of the enterprise (quadrant I). Regarding the secondary benefits of the professional and educational ecosystem (quadrant II), the opinions of the respondents were divided. So, enterprise executives and its structural divisions attributed secondary professional knowledge to secondary advantages, and graduates of ecosystems (enterprise workers) general cultural knowledge. Two other groups of participants (professors and 
students) did not identify any "attribute". Regarding the basic lack of the professional and educational ecosystem (quadrant III), the opinions of the respondents were again divided. Enterprise executives, as well as graduates (enterprise workers), marked the basic lack of obtaining special professional knowledge, and professors - obtaining general professional and general cultural knowledge. In general, the professional and educational ecosystem has confirmed its importance for enterprise in terms of the formation of its human capital, however, the mechanisms for transferring professional knowledge in the ecosystem require further improvement and development.

\section{Conclusions}

The professional and educational ecosystem is a driver for the development of integration of educational organizations and enterprises, the main task of which is to provide enterprises with human capital with the required "quality". The requirements for a certain "quality" of the human capital of the enterprise are set by the features of modern production, due to a change in technological structure, the challenges of global competition and the rapid obsolescence of knowledge in science-based industries. In other words, the professional and educational ecosystem is aimed at achieving unity in the development of productive forces and production relations. The development process of the professional and educational ecosystem itself is based on the complexity of its structure and increased adaptation to changing external conditions based on constant updates.

The effectiveness of a professional and educational ecosystem can be judged by evaluating the results of its functioning. One of the options for assessing the socio-economic ecosystem can be the application of the theory of "stakeholders" and a direct subjective methodology based on a survey of various groups of ecosystem participants. The assessment of the professional and educational ecosystem of the helicopter-building enterprise as a whole indicates its effectiveness. Participants of the professional and educational ecosystem noted that its basic advantage is the acquisition of practical skills by carriers of the human capital of the enterprise. Prospects for the development of the professional and educational ecosystem are seen in strengthening the collaboration of its participants and expanding their composition.

\section{References}

1. Karpinskaya V.A. Ecosystem as a unit of economic analysis. Systemic problems of domestic mesoeconomics, microeconomics, enterprise economics: materials of the Second Conference of the Department for modeling production facilities and complexes of the Central Economic Mathematical Institute of the Russian Academy of Sciences (Moscow, January 12, 2018). M .: Central Economic Mathematical Institute, 2018

2. Kleiner G.B. The enterprise ecosystem in the light of systemic economic theory/Strategic planning and enterprise development: proceedings of the Nineteenth All-Russian Symposium. Moscow, April 10-11, 2018 M.: Central Economic Mathematical Institute of the Russian Academy of Sciences, 2018. Section 1.

3. Kleiner G.B. Socio-economic ecosystems in the light of the system paradigm. System Analysis in Economics - 2018: Proceedings of the V International Scientific and Practical Conference - Biennale (November 21-23, 2018)/Ed. by G.B. Kleiner, S.E. Schepetova. M.: Prometheus, 2018. p. 5-14

4. Kuzmichev A.D. Economic policy and lean production // World of the new economy. 2016. - No. 3. p.46-53 
5. Maltseva V. A. The skill mismatch concept and the problem of assessing the mismatch of cognitive skills // Educational Issues. - 2019. - №3. p.43-76

6. Monitoring the employment of graduates. Ministry of Science and Education of the Russian Federation, M., 2017

7. Popov E.V., Simonova V.L., Tikhonova A.D. A factor model for the development of innovative ecosystems // Innovations. - 2019. - No. 10 (252). p. 88-100

8. Falko S.G., Ivanova N.U., Ankudinova M.L. Features of the formation of the human capital in innovative organizations/Innovation Management - 2018: Materials of an international scientific and practical conference/Ed. by R.M. Nizhegorodskiy, N.P. Goridko- Novocherkassk: Platov South-Russian State Polytechnic University (NPI), 2018. p.65-71

9. Flek M.B., Ugnich E.A. Professional and educational cluster as an ecosystem: 146-159 development in a digital transformation // Journal of Economic Regulation. 2018. Vol. 9, No. 4. p. $146-159$

10. Flek M.B., Ugnich E.A. The role of the basic department in the formation of the human capital of the enterprise // Public Administration. Electronic bulletin. 2018. No. 67. p.293313

11. Human capital: theory and practice of management in socio-economic systems: monograph/ed. by R. M. Nizhegorodtseva and S. D. Reznik. - M .; Penza, 2008 .-- 394 p.

12. Flek M.B., Ugnich E.A. Human Capital Formation of the Enterprise: the Role and Experience of the Specialized Department of the Pillar University // Advances in Economics, Business and Management Research. - 2019. - Vol.79. P. 289-291 DOI: https://doi.org/10.2991/iscfec-19.2019.81

13. Freeman R. E. Strategic Management: A Stakeholder Approach. - Boston, 1984

14. Moore J.F. Predators and prey: A new ecology of competition. Harvard Business Review, May-June, 1993

15. Galport, N., Azzam, T. Evaluator Training Needs and Competencies: A Gap Analysis // American Journal of Evalution. 2017. Vol.38. No1. P.80-100

16. Jarvi, K, Almpanopoulou, A., Ritala, P. Organization of knowledge ecosystem: Prefigurative and partial forms // Research Policy. 2018. 47(8). P.1523-1537

17. Pravdiuk N., Pokynchereda V., Pravdiuk M. The human capital of an enterprise: theory and assessment methodology // Baltic Journal of Economic Studies. - 2019. №2. Vol.5. P.176-183 DOI: https://doi.org/10.30525/2256-0742/2019-5-2-176-183

18. Schwab K. The Fourth Industrial Revolution. Crown Business, New York, 2017

19. Remington T. F. Public-Private Partnerships in VET: Translating the German Model of Dual Education/National Research University Higher School of Economics, Institute of Education. Moscow: HSE Publishing House, 2017

20. Yin R.K. Case Study Research Design and Methods. Thousand Oaks, CA: Sage, 2003 